\title{
BMJ Global Health Effects of improved complementary feeding and improved water, sanitation and hygiene on early child development among HIV-exposed children: substudy of a cluster randomised trial in rural Zimbabwe
}

\author{
Jaya Chandna (iD , ${ }^{1}$ Robert Ntozini (D) ,2 Ceri Evans, ${ }^{3}$ Gwendoline Kandawasvika, ${ }^{4}$ \\ Bernard Chasekwa, ${ }^{2}$ Florence D Majo, ${ }^{2}$ Kuda Mutasa, ${ }^{2}$ Naume V Tavengwa, ${ }^{2}$ \\ Batsirai Mutasa, ${ }^{2}$ Mduduzi NN Mbuya (D) , ${ }^{5}$ Lawrence H Moulton, ${ }^{6}$ \\ Jean H Humphrey, ${ }^{6}$ Andrew J Prendergast, ${ }^{3}$ Melissa Gladstone (D) , ${ }^{1}$ The SHINE \\ Trial Team
}

To cite: Chandna J, Ntozini R, Evans $\mathrm{C}$, et al. Effects of improved complementary feeding and improved water, sanitation and hygiene on early child development among HIVexposed children: substudy of a cluster randomised trial in rural Zimbabwe. BMJ Global Health 2020;5:e01718. doi:10.1136/ bmjgh-2019-001718

Handling editor Seye Abimbola

- Additional material is published online only. To view please visit the journal online (http://dx.doi.org/10.1136/ bmjgh-2019-001718).

Received 16 May 2019 Revised 29 November 2019 Accepted 10 December 2019

Check for updates

(C) Author(s) (or their employer(s)) 2020. Re-use permitted under CC BY. Published by BMJ.

For numbered affiliations see end of article.

Correspondence to

Ms Jaya Chandna;

jayachandna1@gmail.com

\section{ABSTRACT}

Introduction HIV-exposed uninfected children may be at risk of poor neurodevelopment. We aimed to test the impact of improved infant and young child feeding (IYCF) and improved water, sanitation and hygiene (WASH) on early child development (ECD) outcomes.

Methods Sanitation Hygiene Infant Nutrition Efficacy was a cluster randomised $2 \times 2$ factorial trial in rural Zimbabwe ClinicalTrials.gov NCT01824940). Pregnant women were eligible if they lived in study clusters allocated to standard-of-care (SOC; 52 clusters); IYCF (20 g small-quantity lipid-based nutrient supplement/ day from 6 to 18 months, complementary feeding counselling; 53 clusters); WASH (pit latrine, 2 handwashing stations, liquid soap, chlorine, play space, hygiene counselling; 53 clusters) or IYCF +WASH (53 clusters). Participants and fieldworkers were not blinded. ECD was assessed at 24 months using the Malawi Developmental Assessment Tool (MDAT; assessing motor, cognitive, language and social skills); MacArthur Bates Communication Development Inventories (assessing vocabulary and grammar); Anot-B test (assessing object permanence) and a selfcontrol task. Intention-to-treat analyses were stratified by maternal HIV status.

Results Compared with SOC, children randomised to combined IYCF +WASH had higher total MDAT scores (mean difference $+4.6 ; 95 \% \mathrm{Cl} 1.9$ to 7.2 ) and MacArthur Bates vocabulary scores (+8.5 words; $95 \% \mathrm{Cl} 3.7$ to 13.3), but there was no evidence of effects from IYCF or WASH alone. There was no evidence that that any intervention impacted object permanence or self-control. Conclusions Combining IYCF and WASH interventions significantly improved motor, language and cognitive development in HIV-exposed children. Trial registration number NCT01824940.
Key questions

What is already known?

- Globally, an estimated $43 \%$ of children fail to reach their full developmental potential.

- The population of HIV-exposed uninfected (HEU) children is expanding, and reached nearly 15 million in 2017.

- Children who are HEU may be at greater risk of poor early child development than HIV-unexposed children.

What are the new findings?

- Compared with standard-of-care, children randomised to combined infant and young child feeding (IYCF) plus water, sanitation and hygiene (WASH) had higher total child development scores as measured by the Malawi Developmental Assessment Tool (mean difference $+4.6 ; 95 \% \mathrm{Cl} 1.9$ to 7.2 ).

- Compared with standard-of-care, children randomised to combined IYCF+WASH had higher MacArthur Bates vocabulary scores (+8.5 words; $95 \% \mathrm{Cl} 3.7$ to 13.3).

- There was no evidence that IYCF or WASH alone affected child development.

What do the new findings imply?

- HEU children may be particularly responsive to a package of public health interventions, which may support a targeted intervention approach to ensure that HEU children survive, thrive and reach their full potential.

\section{INTRODUCTION}

Globally, 1.4 million HIV-infected women become pregnant each year, predominantly 
in sub-Saharan Africa. Due to increased coverage of prevention of mother-to-child transmission (PMTCT) interventions, the number of HIV-exposed uninfected (HEU) children is expanding, and reached nearly 15 million in 2017. ${ }^{1}$ HEU children have higher mortality and more frequent and more severe infections, anaemia and growth faltering than children born to HIV-negative mothers (HIV-unexposed children). ${ }^{2}$ Since stunting (linear growth faltering), ${ }^{3}$ anaemia ${ }^{4}$ and inflammation ${ }^{5}$ are all associated with impaired neurodevelopment, HEU children may be at greater risk of poor early child development (ECD) than HIV-unexposed children, although empirical evidence is limited. ${ }^{6}$ Together these observations suggest that interventions to reduce stunting, anaemia and infections may have particular benefits for the growing population of HEU children, including enhanced neurodevelopment.

The Sanitation Hygiene Infant Nutrition Efficacy (SHINE) trial was designed to assess the individual and combined effects of an infant and young child feeding (IYCF) intervention and a household water, sanitation and hygiene (WASH) intervention on stunting and anaemia in HIV-unexposed and HIV-exposed Zimbabwean children. ${ }^{7}$ The WASH intervention was designed to reduce exposure to faecal microbes, and thereby prevent a subclinical inflammatory disorder of the gut termed environmental enteric dysfunction (EED), which may mediate stunting, anaemia and reduced ECD. We previously reported that the IYCF intervention reduced stunting and anaemia in HIV-unexposed ${ }^{8}$ and HIV-exposed ${ }^{9}$ children at 18 months of age, but the WASH intervention had no impact on either of these trial outcomes. A substudy, assessing the effects of the randomised interventions on ECD at 24 months of age, showed there was overall little impact of either intervention on neurodevelopment among HIV-unexposed children. ${ }^{10}$ Here, we report the impact of the randomised interventions on ECD at 24 months among HIV-exposed children, in whom we hypothesised the trial interventions may have distinct effects compared with HIV-unexposed children.

\section{METHODS}

\section{Study design and randomisation}

The SHINE trial design has been reported previously; the protocol and statistical analysis plan are available at https://osf.io/w93hy Briefly, SHINE was a cluster randomised, community-based $2 \times 2$ factorial trial conducted in two contiguous rural districts in Zimbabwe. Clusters were defined as the catchment area of $1-4$ village health workers (VHWs) employed by the Ministry of Health and Child Care, and were allocated to one of four treatment groups (standard-of-care (SOC), IYCF, WASH, IYCF + WASH) at a public randomisation event. A highly constrained randomisation technique achieved balance across arms for 14 variables related to geography, demography, water access and sanitation coverage. Between 22
November 2012 and 27 March 2015, VHWs identified pregnant women and referred them to trial research nurses, who enrolled women permanently residing in the study area into SHINE following written informed consent. HIV prevalence among antenatal women in the study area was $15 \%$; we prespecified that analysis of all outcomes would be stratified by maternal HIV status.

\section{Trial interventions}

Interventions were informed by extensive formative research and piloting. ${ }^{7}$ Behavioural change modules using interactive tools to deliver specific messages were provided by arm-specific VHWs; lesson plans and intervention tools are publicly accessible at https://osf.io/ w93hy. All women were scheduled to receive 15 VHW visits between enrolment and 12 months postpartum; other family members were encouraged to participate. At each visit, previous information was reviewed before introducing new information to create a sequenced, integrated, longitudinal intervention. Between 13 and 17 months, VHWs visited monthly, providing routine care and, in active arms, delivering intervention supplies; during these visits VHWs informally encouraged participants to practise relevant behaviours. At 18 months, a review module was delivered in all arms. Key messages and supplies are outlined below, with more detail provided in the online supplementary methods:

- SOC Promotion of exclusive breast feeding to 6 months, uptake of antenatal and neonatal care, PMTCT, immunisations, family planning.

- IYCF All SOC messages plus (1) importance of nutrition for infant health, growth and development; (2) feeding nutrient-dense food and $20 \mathrm{~g}$ small-quantity lipid-based nutrient supplement (SQ-LNS; Nutriset, Malaunay, France) daily from 6 to 18 months; (3) processing locally available foods to facilitate mastication and swallowing; (4) feeding during illness; (5) dietary diversity. Monthly delivery of SQ-LNS from 6 to 18 months.

- WASH All SOC messages plus (1) safe disposal of faeces; (2) hand-washing with soap at key times; (3) protection of infants from geophagia and animal faeces ingestion; (4) chlorination of drinking water and (5) hygienic preparation of complementary food. Ventilated improved pit latrine constructed within 6 weeks of enrolment; two hand-washing stations; plastic mat and play yard; monthly delivery of soap and chlorine (WaterGuard, Nelspot, Zimbabwe).

IYCF+WASH All SOC, IYCF and WASH interventions.

A latrine was constructed in non-WASH arms following trial completion. Masking for participants and fieldworkers was not possible, but investigators were blinded to trial arm.

\section{Maternal HIV testing}

Local clinics undertook antenatal HIV testing and provided antiretroviral therapy (ART) to HIV-positive women. PMTCT guidelines in Zimbabwe changed from 
WHO Option B (combination ART for all HIV-positive women during the pregnancy and breast feeding) to Option B+ (lifelong ART for pregnant and breastfeeding women) during the trial (from November 2013). In addition to local clinic services, we offered home HIV testing to mothers at baseline using an anti-HIV antibody rapid test algorithm (Alere Determine HIV-1/2 test, confirmed by INSTI HIV-1/2 test if positive); testing was repeated at 32 gestational weeks to detect HIV seroconversion during pregnancy. Women testing HIV-positive had CD4 counts measured (Alere Pima, Abbott) and were referred to local clinics for ART. The trial did not measure HIV viral loads.

\section{Child HIV testing}

HIV-positive women were encouraged to attend local clinics at 4-6 weeks post partum for early infant diagnosis, initiation of cotrimoxazole prophylaxis and, for HIV-infected children, ART initiation. Infants born to HIV-positive mothers were eligible for enrolment into a substudy in which biological specimens were collected longitudinally. For substudy infants, blood was tested for HIV (by PCR or rapid test, depending on age and sample) at 1, 3, 6, 12 and 18 months; infants not enrolled into the substudy were tested at 18 months. HEU children were defined as being born to HIV-positive mothers and testing HIV-negative at 18 months of age. HIV-exposed children, who were not tested at 18 months because of maternal refusal, missed visits or failure to obtain a specimen or children who had inconclusive/discordant HIV results after retesting, were classified as HIV unknown. All HIV-positive children were referred to clinics for ART initiation.

\section{Data collection}

Research nurses made home visits at baseline ( 2 weeks after consent), 32 weeks' gestation and at 1, 3, 6, 12 and 18 months postpartum to assess maternal and household characteristics and trial outcomes. Intervention uptake was assessed by participant behaviours at the 12-month postnatal visit.

\section{ECD substudy}

Infants who completed the trial and turned 2 years of age (allowable range 102-112 weeks) between 1 March 2016 and 30 April 2017 were eligible to join the ECD substudy. Children were enrolled either during the 18-month trial endpoint visit, or following the 18 month SHINE visit but before the child turned 2 years of age.

\section{Assessment tools}

A team of 11 research nurses completed 3 weeks of residential training in ECD assessment by the team psychologist (JC) and a neurodevelopmental paediatrician (MG). Several domains of ECD were assessed.

1. Malawi Developmental Assessment Tool (MDAT), measuring child development in four domains: gross and fine motor coordination, language and social. Fine motor, language and social domains also measure components of cognitive development. ${ }^{11}$ The MDAT was initially validated in Malawi (a very similar setting to Zimbabwe) and then piloted on 50 Zimbabwean children.

2. MacArthur Bates Communicative Development Inventories (CDI), assessing language according to maternal report using vocabulary and grammar checklists. ${ }^{12}$ The test was specifically adapted for Shona speakers using a detailed protocol approved by the CDI team. ${ }^{13} 14$

3. A-not-B test, assessing object permanence and cognition. $^{15}$

4. Self-control task, assessing impulsivity. ${ }^{16}$

\section{Study outcomes}

The ECD substudy design and outcomes were prespecified in the study protocol and statistical analysis plan (https://osf.io/w93hy). The primary outcomes were MDAT total (out of 138), gross motor (out of 36), fine motor (out of 36), social (out of 30) and language (out of 36) scores; MacArthur Bates CDI vocabulary checklist (number of words known out of 99); A-not-B score (out of 10); and the proportion of children with self-control. The secondary outcomes were the proportion of children using the progressive tense, using plurals or combining two words (MacArthur Bates CDI grammar checklist).

Children with severe motor, visual, hearing or learning impairments as determined by the Washington Group questionnaire (child version) ${ }^{17}$ were excluded from analyses and referred to local clinics.

\section{Validation and quality control}

Every 6 months, nurses underwent refresher training and standardisation. Each nurse was observed while conducting an ECD assessment while a gold-standard assessor double-scored the assessment; percentage agreement had to be $>85 \%$ for certification, with retraining and retesting required for those who did not meet this threshold. In addition, all 11 nurses concurrently scored the same child: average interclass correlations across standardisations were: MDAT 0.88 (95\% CI 0.82 to 0.94 ); MacArthur Bates 0.94 (95\% CI 0.90 to 0.96); A-not-B 0.85 (95\% CI 0.80 to 0.90$)$ and self-control task $0.80(95 \%$ CI 0.76 to 0.85 ). Supportive supervision was undertaken during monthly field visits and nurses were provided with corrective or reinforcing feedback. A 5\% subsample of assessments were video recorded, reviewed and double scored by a psychologist (JC) and a neurodevelopmental paediatrician with Shona language proficiency (GK). Percentage agreement for these video-taped assessments was $93 \%$ for MDAT fine motor, $90 \%$ for MDAT language, 97\% for A-not-B and $91 \%$ for the self-control task.

\section{Statistical analysis}

All analyses were intention to treat at the child level. The absolute difference in mean score between treatment groups was estimated for tests with continuous outcomes. For tests with dichotomous outcomes, the relative risk (RR) of passing was compared between treatment 
groups. Primary analyses used generalised estimating equations to account for within-cluster correlation, containing two dummy variables for the two interventions, representing the main effect of the IYCF intervention (the two IYCF-containing groups compared with the two groups without IYCF) and the WASH intervention (the two WASH-containing groups compared with the two groups without WASH), unadjusted for other covariates, with an exchangeable working correlation structure. For each outcome, we estimated the statistical interaction between the IYCF and WASH interventions. When the interaction was significant $(\mathrm{p}<0.05$ according to the Wald test), results are based on a regression model with three dummy variables to represent IYCF, WASH and IYCF + WASH compared with SOC, instead of the model with two terms. Adjusted analyses controlled for prespecified baseline covariates (mother's mid-upper arm circumference, mother's education, mother's employment, maternal health perception, maternal capabilities, improved latrine, low birth weight, prematurity, sex, calendar month, fieldworker, decimal age), which were initially assessed in bivariate analyses to identify those with an important association with the outcome (for dichotomous outcomes: $\mathrm{p}<0.2$ or $\mathrm{RR}>2.0$ or $<0.5$; for continuous outcomes: $\mathrm{p}<0.2$ or difference $>0.25 \mathrm{SD}$ ). Selected covariates were entered in a multivariable regression model; a forward stepwise selection procedure was implemented with $\mathrm{p}<0.2$ to enter. A log-binomial specification was used to estimate RRs. Methods for comparing study arms while handling within-cluster correlation included multinomial and ordinal regression models with robust variance estimation, and Somers' D for medians, were all implemented in Stata V.14.

In a sensitivity analysis, HIV-positive and HIVunknown children were excluded. A subgroup analysis by child gender was planned if there was a significant interaction between gender and study arms (as defined above).

\section{Sample size}

The sample size of the ECD substudy was based on detecting clinically relevant differences among HIVunexposed children ${ }^{10}$; there was no specific sample size calculation for HIV-exposed children.

\section{Patient and public involvement}

We did not directly include patient and public involvement in this trial, but all community activities were discussed with traditional and elected leaders in both study districts, who provided advice through the District Health Executive, Social Services Committee and Rural District Council. A film of the SHINE trial is being made with community participation to capture the experience of being involved in a community-wide trial. The film will be screened in the two rural districts where SHINE was conducted.

\section{Role of funder}

Study funders approved the trial design, but were not involved in data collection, analysis or interpretation, nor decisions related to publication. The corresponding author had full access to all study data and ultimate responsibility for the decision to submit for publication.

\section{Trial oversight and registration}

An independent data safety and monitoring board reviewed interim adverse event data.

\section{RESULTS}

Among 5280 enrolled pregnant women, 726 tested HIVpositive during the pregnancy; of 738 infants born to these mothers, 475 were eligible for the ECD substudy, and 323 (68\% of eligible) were enrolled from 142 clusters (figure 1) during the period of enrolment (between 1 March 2016 and 30 April 2017). Of the 152 children not enrolled, $94(62 \%)$ had relocated temporarily or permanently from their study home; 41 (27\%) were not reachable by telephone or home visit to determine availability and interest in joining the ECD substudy; 8 (5\%) declined; 4 (3\%) could not be scheduled at a mutually agreeable time within the required age window; and 3 (2\%) died between 18 and 24 months of age.

\section{Baseline characteristics}

At baseline, approximately half of all household members practised open defecation, and just over one-third had a household latrine (table 1). About $40 \%$ of households consumed a minimally diverse diet. Among mothers, mean (SD) CD4 count was 461 (218) cells $/ \mu \mathrm{L} ; 88 \%$ and $67 \%$ received ART and cotrimoxazole, respectively, during the pregnancy. There were some minor baseline imbalances in improved latrine ownership, observed chicken faeces in households, wealth index, mode of delivery and birth weight between arms. HIV-positive mothers who enrolled in the ECD substudy were about 3 years older than those who did not enrol, SOC and IYCF +WASH enrolled mothers had higher institutional delivery (92\% vs $74 \%$ ) while IYCF and WASH arms were similar; other baseline characteristics of mother-infant dyads who enrolled or did not enrol were similar (online supplementary table 1 ).

\section{Delivery and uptake of interventions}

Across randomised arms, the fidelity of providing intervention supplies (WASH hardware, liquid soap, chlorine and SQ-LNS) was high, and $>90 \%$ of expected behavioural change modules were delivered by VHWs (table 2). Open defecation was virtually eliminated in the WASH arms: $<1 \%$ households reported practising open defecation compared with half in non-WASH arms. Among WASH compared with non-WASH households, fewer mothers reported ever seeing their child ingest soil and chicken faeces. Over $90 \%$ of children in all treatment arms were still breast feeding at 12 months. A higher proportion of infants in the IYCF arms had consumed a diet that met 


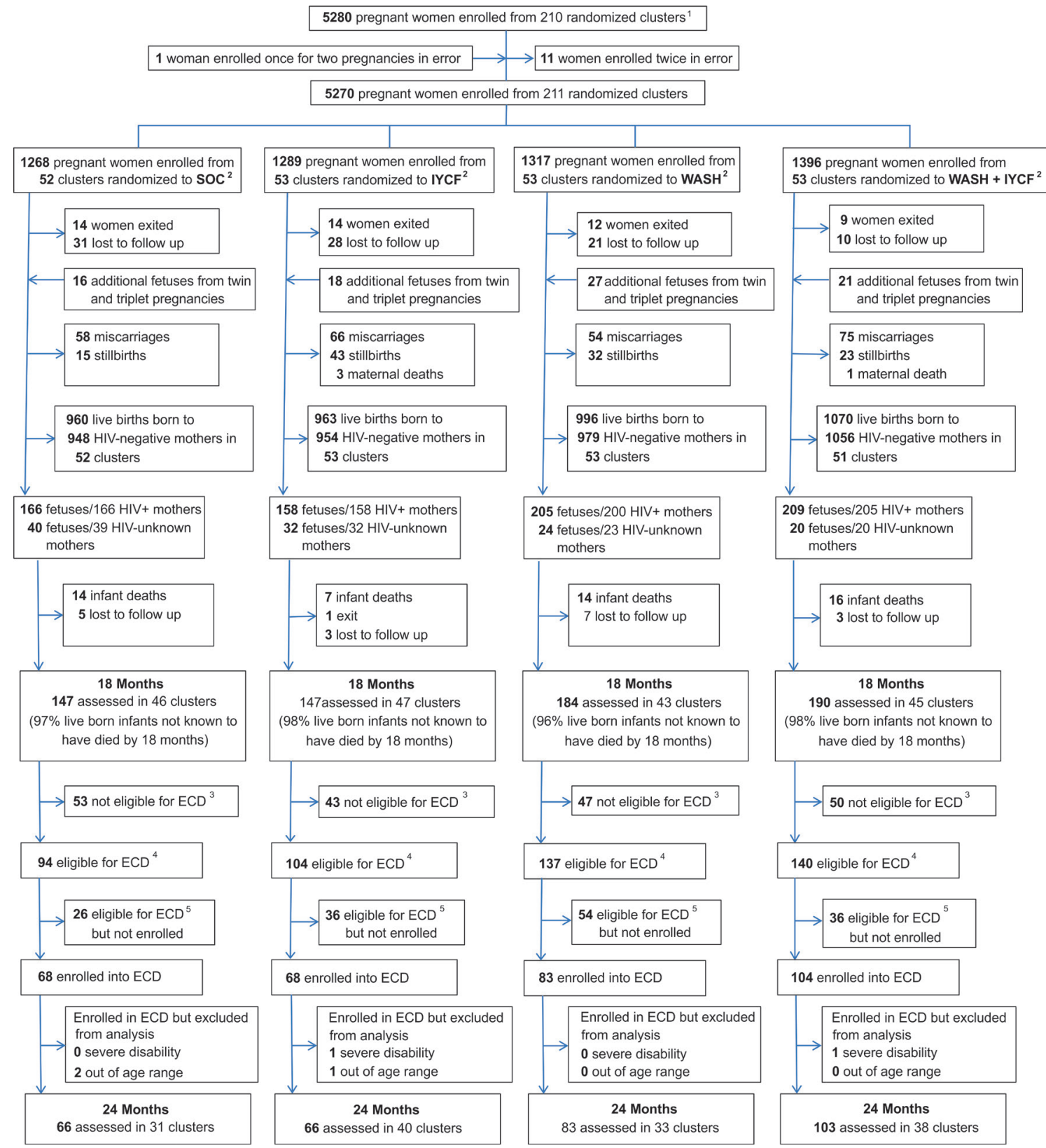

Figure 1 Flow of participants through the trial. $1 \mathrm{~A}$ total of 212 clusters were randomised, 53 in each of the four trial arms. After randomisation, one cluster was excluded as it was determined to be in an urban area, one cluster was excluded as the VHW covering it mainly had clients outside the study area, and one more was merged into a neighbouring cluster based on subsequent data on VHW coverage. Three new cluster designations were created due to anomalies in the original mapping: for two of these, the trial arm was clear; the third contained areas that were in two trial arms and was assigned to the underrepresented arm, resulting in 53 clusters in each arm. All of this occurred before enrolment began. When enrolment was completed, however, there was one cluster (SOC) in which no women were enrolled, leaving a total of 211 clusters available for analysis. 2IYCF, infant and young child feeding; SOC, standard- of-care; WASH, water, sanitation and hygiene. 3Children were not eligible for the early child development (ECD) substudy if they turned 2 years of age (allowable range 102-112 weeks) before 1 March 2016. 4Children were eligible for the ECD substudy if they turned 2 years of age (allowable range 102-112 weeks) between 1 March 2016 and 30 April 2017. 5A total of 152 children were eligible but not enrolled: 94 (62\%) had relocated temporarily or permanently from their study home; $41(27 \%)$ were not reachable by telephone or home visit to determine availability and interest in joining the ECD substudy; $8(5 \%)$ declined; $4(3 \%)$ could not be scheduled at a mutually agreeable time within the required age window; and $3(2 \%)$ died between 18 and 24 months of age. VHW, village health worker.

minimum dietary diversity and had consumed animalsource, iron-rich and vitamin A-rich foods in the previous day. Almost all children in the IYCF arms had consumed SQ-LNS in the previous 24 hours.

\section{Effect of randomised intervention on ECD outcomes}

The age at the ECD assessment visit was very similar across trial arms (SOC: mean (SD) 105.4 (2.2) weeks; IYCF: 105.0 (2.0) weeks; WASH: 105.1 (1.9) weeks and 
Table 1 Maternal, household and infant baseline characteristics of HIV-positive mothers and their liveborn infants in the early child development substudy

\begin{tabular}{|c|c|c|c|c|}
\hline Baseline characteristics* & Standard-of-care & IYCF & WASH & IYCF+WASH \\
\hline Mothers & 68 & 67 & 81 & 102 \\
\hline Infants & 68 & 68 & 83 & 104 \\
\hline Mothers completing baseline visit & 67 & 65 & 80 & 101 \\
\hline \multicolumn{5}{|l|}{ Household characteristics } \\
\hline Median no of occupants (IQR) & $5(3-6)$ & $4(3-6)$ & $5(3-6)$ & $4(3-6)$ \\
\hline \multicolumn{5}{|l|}{ Wealth quintile: $†$} \\
\hline 1 (lowest) & $16 / 68(23.5 \%)$ & $14 / 67(20.9 \%)$ & $20 / 81(24.7 \%)$ & $28 / 102(27.5 \%)$ \\
\hline 2 & $16 / 68(23.5 \%)$ & 13/67 (19.4\%) & $15 / 81(18.5 \%)$ & $19 / 102(18.6 \%)$ \\
\hline 3 & $12 / 68(17.7 \%)$ & $13 / 67(19.4 \%)$ & $19 / 81(23.5 \%)$ & $17 / 102(16.7 \%)$ \\
\hline 4 & 8/68 (11.8\%) & $17 / 67(25.4 \%)$ & $11 / 81(13.6 \%)$ & $17 / 102(16.7 \%)$ \\
\hline 5 (highest) & $14 / 68(20.6 \%)$ & $8 / 67(11.9 \%)$ & $13 / 81(16.1 \%)$ & $19 / 102(18.6 \%)$ \\
\hline \multicolumn{5}{|l|}{ Electricity } \\
\hline Connected to power grid & $3 / 66(4.6 \%)$ & $3 / 65(4.6 \%)$ & $0 / 78(0.0 \%)$ & $3 / 100(4.0 \%)$ \\
\hline \multicolumn{5}{|l|}{ Other power source } \\
\hline Use a generator & $2 / 66(3.0 \%)$ & $3 / 65(4.6 \%)$ & $0 / 78(0.0 \%)$ & $3 / 100(3.0 \%)$ \\
\hline Use solar power & $45 / 66(68.2 \%)$ & $44 / 65(67.7 \%)$ & $56 / 78(71.8 \%)$ & $64 / 100(64.0 \%)$ \\
\hline No electricity & $19 / 66(28.8 \%)$ & $18 / 65(27.7 \%)$ & $22 / 78(28.2 \%)$ & $33 / 100(33.0 \%)$ \\
\hline \multicolumn{5}{|l|}{ Sanitation } \\
\hline Household members defecate in the open & $177 / 302(58.6 \%)$ & $151 / 282(53.6 \%)$ & $182 / 337(54.0 \%)$ & $196 / 426(46.0 \%)$ \\
\hline Any latrine at household & $18 / 66(27.3 \%)$ & $28 / 62(45.2 \%)$ & $29 / 77(37.7 \%)$ & $37 / 96(38.5 \%)$ \\
\hline Improved latrine at household & $17 / 66(25.8 \%)$ & $24 / 62(38.7 \%)$ & $25 / 77(32.5 \%)$ & $36 / 96(37.5 \%)$ \\
\hline $\begin{array}{l}\text { Improved latrine with well-trodden path and not shared } \\
\text { with other households and not used for storage }\end{array}$ & $12 / 64(18.8 \%)$ & $28 / 60(31.7 \%)$ & $29 / 76(27.6 \%)$ & 23/94 (24.5\%) \\
\hline \multicolumn{5}{|l|}{ Water } \\
\hline Main source of household drinking water is improved & $41 / 66(62.1 \%)$ & $36 / 62(58.1 \%)$ & $44 / 77(57.1 \%)$ & $59 / 96(61.5 \%)$ \\
\hline Treat drinking water to make it safer & $13 / 64(20.3 \%)$ & $11 / 62(17.7 \%)$ & $10 / 77(13.0 \%)$ & $13 / 96(13.5 \%)$ \\
\hline Median one-way walk time to fetch water (IQR); min & $10(5-20)$ & $9(3-15)$ & $10(5-15)$ & $9(5-20)$ \\
\hline $\begin{array}{l}\text { Mean water volume collected per person in past } \\
24 \text { hours (SD); } L\end{array}$ & $8.7(4.6)$ & $9.4(6.7)$ & $9.1(6.7)$ & $10.3(8.2)$ \\
\hline \multicolumn{5}{|l|}{ Hygiene } \\
\hline Hand-washing station at household & $3 / 54(5.6 \%)$ & $4 / 62(6.5 \%)$ & $11 / 74(14.9 \%)$ & $15 / 91(16.5 \%)$ \\
\hline Hand-washing station with water and rubbing agent & $0 / 54(0.0 \%)$ & $0 / 60(0.0 \%)$ & 0/74 (0.0\%) & $1 / 91(1.1 \%)$ \\
\hline Improved floor $\ddagger$ & $31 / 65(47.7 \%)$ & $35 / 65(53.9 \%)$ & $35 / 77(45.5 \%)$ & $48 / 98(49.0 \%)$ \\
\hline Median no of chickens (IQR) & $4(1-8)$ & $6(2-10.5)$ & $5(3-8)$ & $4(1-8)$ \\
\hline Livestock observed inside home & $28 / 66(42.4 \%)$ & $19 / 67(28.4 \%)$ & $34 / 79(43.0 \%)$ & $33 / 99(33.3 \%)$ \\
\hline Faeces observed in yard & $25 / 65(38.5 \%)$ & $18 / 66(27.3 \%)$ & $27 / 78(34.6 \%)$ & $17 / 98(17.4 \%)$ \\
\hline \multicolumn{5}{|l|}{ Diet quality and food security } \\
\hline Household meets minimum dietary diversity§ & $21 / 55(38.2 \%)$ & $22 / 57(38.6 \%)$ & $24 / 74(32.9 \%)$ & $37 / 83(44.6 \%)$ \\
\hline Median Coping Strategies Index scorefl (IQR) & $4(0-9.5)$ & $2(0-15)$ & $3(0-11)$ & $1(0-9)$ \\
\hline \multicolumn{5}{|l|}{ Maternal characteristics } \\
\hline Mean age (SD), years & $30.8(5.7)$ & $30.9(7.2)$ & $30.4(5.7)$ & $30.9(5.8)$ \\
\hline Mean height (SD), cm & $161.3(7.8)$ & $160.3(6.4)$ & $160.5(5.3)$ & $159(6.6)$ \\
\hline Mean mid-upper arm circumference (SD), cm & $26.8(3.4)$ & $26.3(3.6)$ & $26.4(2.2)$ & $26.5(2.8)$ \\
\hline Positive microscopy for Schistosoma haematobium & $6 / 67(9.0 \%)$ & $4 / 65(6.2 \%)$ & $12 / 78(15.4 \%)$ & $9 / 101(8.9 \%)$ \\
\hline Mean years of completed schooling (SD) & $9.5(1.8)$ & $9.1(2.1)$ & $8.7(2.2)$ & $9.3(2.1)$ \\
\hline Median parity (IQR) & $3(1-3)$ & $2(1-3)$ & $3(2-4)$ & $2(1-3)$ \\
\hline Married & $61 / 64(95.3 \%)$ & $59 / 63(93.7 \%)$ & $71 / 73(97.3 \%)$ & 85/92 (92.4\%) \\
\hline
\end{tabular}




\begin{tabular}{|c|c|c|c|c|}
\hline Baseline characteristics* & Standard-of-care & IYCF & WASH & IYCF+WASH \\
\hline Employed & $5 / 65(7.7 \%)$ & $5 / 65(7.7 \%)$ & $8 / 78(10.3 \%)$ & 8/100 (8.0\%) \\
\hline \multicolumn{5}{|l|}{ Religion } \\
\hline Apostolic & $34 / 63(54.0 \%)$ & $32 / 63(50.8 \%)$ & $34 / 74(46.0 \%)$ & $46 / 93(49.5 \%)$ \\
\hline Other christian religions & 25/63 (39.7\%) & $25 / 63(39.7 \%)$ & $30 / 74(40.5 \%)$ & $41 / 93(44.1 \%)$ \\
\hline Other & $4 / 63(6.4 \%)$ & $6 / 63(9.5 \%)$ & $10 / 74(13.5 \%)$ & $6 / 93(6.5 \%)$ \\
\hline \multicolumn{5}{|l|}{ HIV disease severity and treatment } \\
\hline Mean CD4 count in pregnancy (SD) $)^{\star \star}$, cells/ $\mu \mathrm{L}$ & $474(180)$ & $478(186)$ & $421(187)$ & $470(217)$ \\
\hline Antiretroviral therapy during pregnancy†† & $60 / 68(88.2 \%)$ & $60 / 67(89.6 \%)$ & $65 / 81(80.3 \%)$ & $90 / 102(88.2 \%)$ \\
\hline Cotrimoxazole prophylaxis during pregnancył & $40 / 68(58.8 \%)$ & $42 / 67(62.7 \%)$ & $55 / 81(67.9 \%)$ & $63 / 102(61.8 \%)$ \\
\hline \multicolumn{5}{|l|}{ Infant characteristics } \\
\hline Female & $33 / 68(48.5 \%)$ & $32 / 63(47.1 \%)$ & $39 / 83(47.0 \%)$ & $55 / 104(52.9 \%)$ \\
\hline Mean birth weight (SD), kg & $3.03(0.45)$ & $2.94(0.49)$ & $3.07(0.66)$ & $3.02(0.50)$ \\
\hline Low birth weight $<2500 \mathrm{~g}$ & 8/68 (11.8\%) & $10 / 68(14.7 \%)$ & $6 / 83(7.2 \%)$ & $11 / 104(10.6 \%)$ \\
\hline Institutional delivery & $59 / 64(92.2 \%)$ & $55 / 66(83.3 \%)$ & $67 / 79(84.8 \%)$ & $85 / 92(92.4 \%)$ \\
\hline Vaginal delivery & 62/66 (93.9\%) & $57 / 62(87.7 \%)$ & $76 / 80(95.0 \%)$ & 90/98 (91.8\%) \\
\hline
\end{tabular}

*Baseline variables presented for mothers who had live births; maternal and household data were collected about 2 weeks after consent $(\sim 14$ weeks gestation); this gap created opportunity for lost to follow-up between consent and baseline, thus the number of mothers completing the baseline visit is fewer than the number of mothers with live births. Baseline for infants was at birth. Values are \%, unless noted. For variables where ( $\mathrm{n})$ is not stated, $<3 \%$ of data are missing based on number of baseline visits completed.

†Chasekwa et al. ${ }^{23}$

†Improved floor defined as concrete, brick, cement or tile. Unimproved floor defined as mud, earth, sand or dung.

§FAO, FHI 360. Minimum Dietary Diversity for Women: A Guide for Measurement. Rome: FAO. 2016.

ๆMaxwell et al. ${ }^{24}$

${ }^{*} \mathrm{CD} 4$ count at baseline visit, or at 32 gestational week visit if no baseline result.

††Includes any exposure to antiretroviral therapy during pregnancy; Includes anydocumented exposure to anti-retroviral therapy during pregnancy. $\ddagger \ddagger$ Includes any exposure to co-trimoxazole during pregnancy; Includes any documented exposure to co-trimoxazole during pregnancy.

IYCF, infant and young child feeding; WASH, water, sanitation and hygiene.

IYCF+WASH 105.6 (2.1) weeks). Of the 323 enrolled children, two $(1 \%)$ were excluded due to severe disability, and three $(1 \%)$ were excluded because they were subsequently found to be outside the predefined age window (102-112 weeks). Two children (both in the IYCF+WASH arm) were assessed after the substudy enrolment period ended, but were otherwise eligible and were included. The final analysis therefore included 318 HIV-exposed children (figure 1), of whom 6 were HIVpositive, $300 \mathrm{HEU}$ and $12 \mathrm{HIV}-$ unknown.

There was a significant interaction between the WASH and IYCF interventions for the total MDAT score and MacArthur Bates CDI vocabulary checklist; therefore, scores for these tests were analysed and presented separately for the four treatment arms. There was no interaction between the randomised interventions for the object permanence and self-control tests; therefore, the main effects of IYCF and WASH are presented for these tests.

\section{MDAT scores}

At 24 months, the total MDAT score was higher among children in the IYCF +WASH group compared with the SOC group (unadjusted difference +4.6 ; $95 \%$ CI 1.9 to 7.2). This difference corresponds to a $0.50 \mathrm{SD}$ increase in total MDAT score, and was driven by higher scores in all components of the MDAT test (table 3). In adjusted analyses, the total MDAT score remained significantly higher in the IYCF +WASH group (adjusted difference +3.1 ; $95 \%$ CI 0.9 to 5.3 ); differences in individual components of the MDAT score were attenuated and no longer reached statistical significance for the fine motor and language component scores. There was no evidence of effect from the IYCF or WASH interventions alone, either on total MDAT score or any of the MDAT component scores.

\section{MacArthur Bates CDI vocabulary and grammar checklists}

Compared with SOC, children in the IYCF +WASHarm had higher MacArthur Bates CDI vocabulary scores (+8.5 words; $95 \%$ CI 3.7 to 13.3), corresponding to an increase of $0.44 \mathrm{SD}$. Twice as many children in the IYCF +WASH arm reportedly used plurals (RR 2.08; 95\% CI 0.98 to 4.41 ), although this difference was no longer significant in the adjusted analysis. There was no evidence of an effect of IYCF +WASH on the proportion of children combining two words or using the progressive tense. There was no evidence that either the IYCF or WASH interventions, when implemented alone, impacted any component of the MacArthur Bates CDI score (table 3).

\section{Object permanence and self-control}

There was no interaction between interventions for either test, so the IYCF arms were compared with nonIYCF arms, and the WASH arms were compared with 


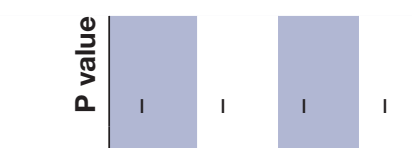

远

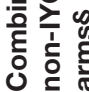

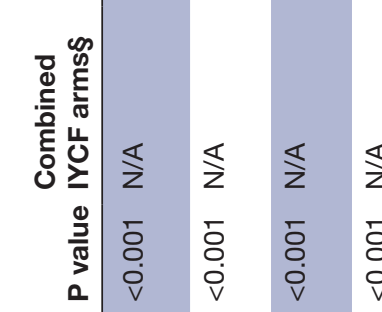

马 龺

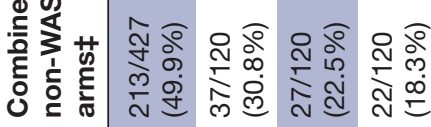

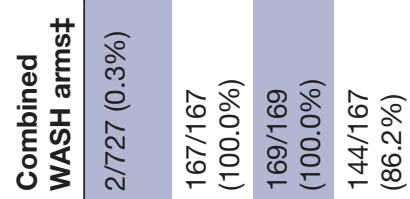

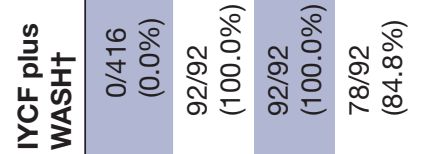

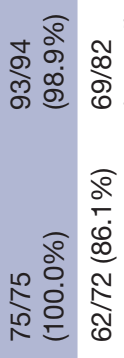

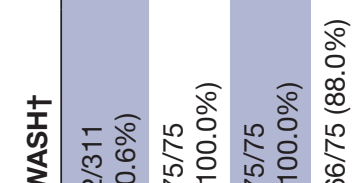

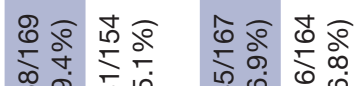

ㅇํㅇำำ ㅇํㅇ

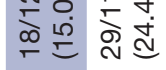

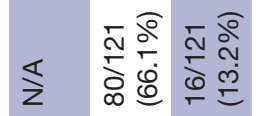

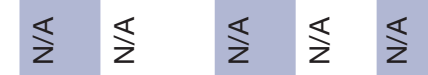

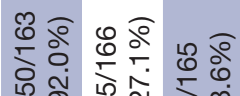
o

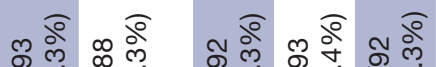
ळ.

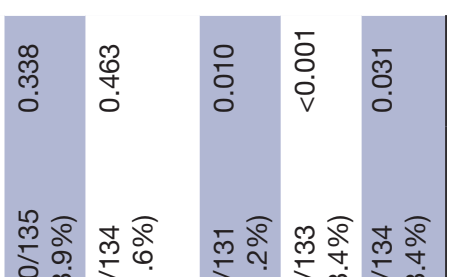

구요

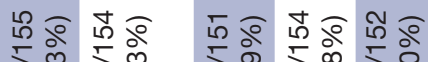

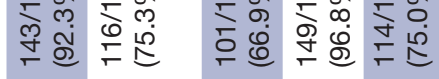
$\frac{\pi}{z} \quad \ll \quad \ll$

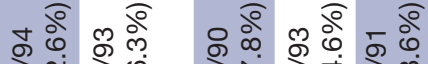
क वें

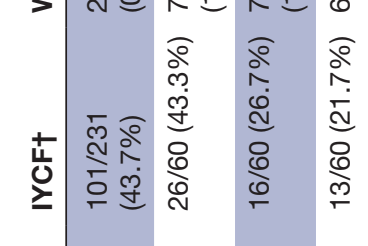
ঠ্口.

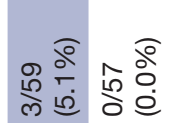

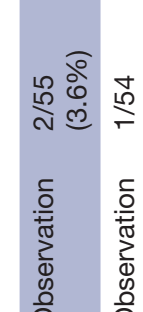

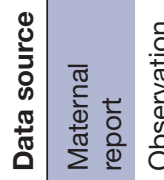

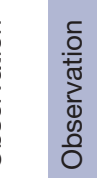

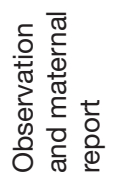

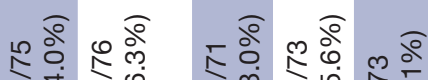
लु

১े すे

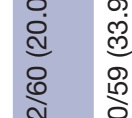

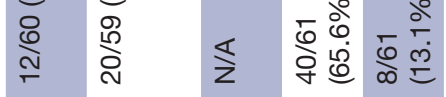

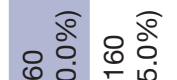
일 के

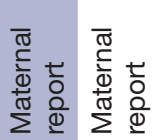
舫

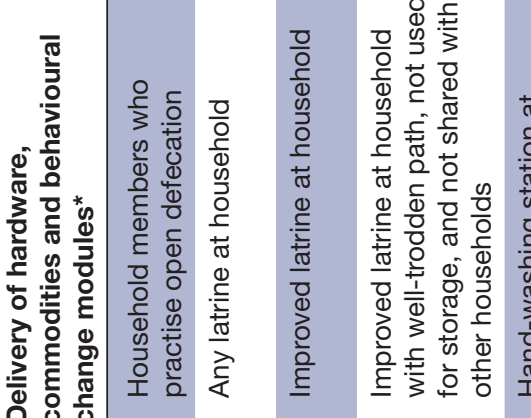

$\circ \quad 5$

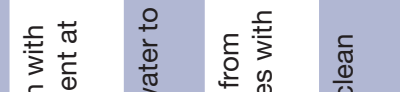

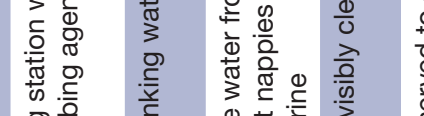

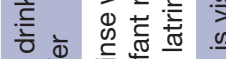

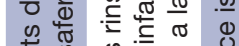

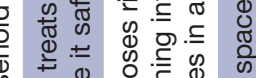
के

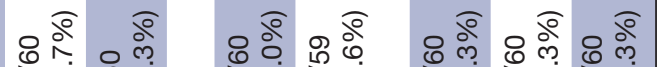

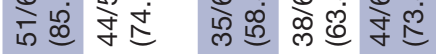

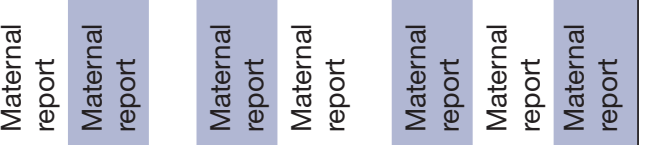

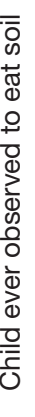

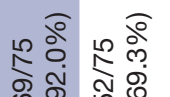

ㄷำ

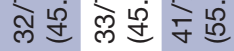

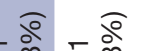

-

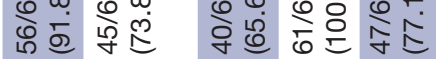

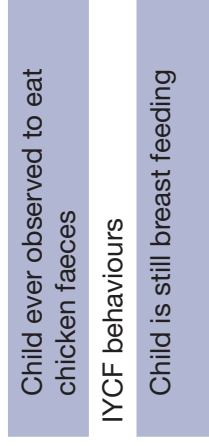

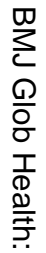

$\stackrel{\vec{F}}{\stackrel{9}{+}}$

$\frac{\bar{C}}{\frac{\bar{O}}{\bar{W}}}$

๓)

$\vec{\omega}$

을.

옹

8

$\vec{\sim}$

옥

$\vec{\omega}$

ڤ్ల

N

¿ำ

०े

홍

䪞

윽

모․

옥 


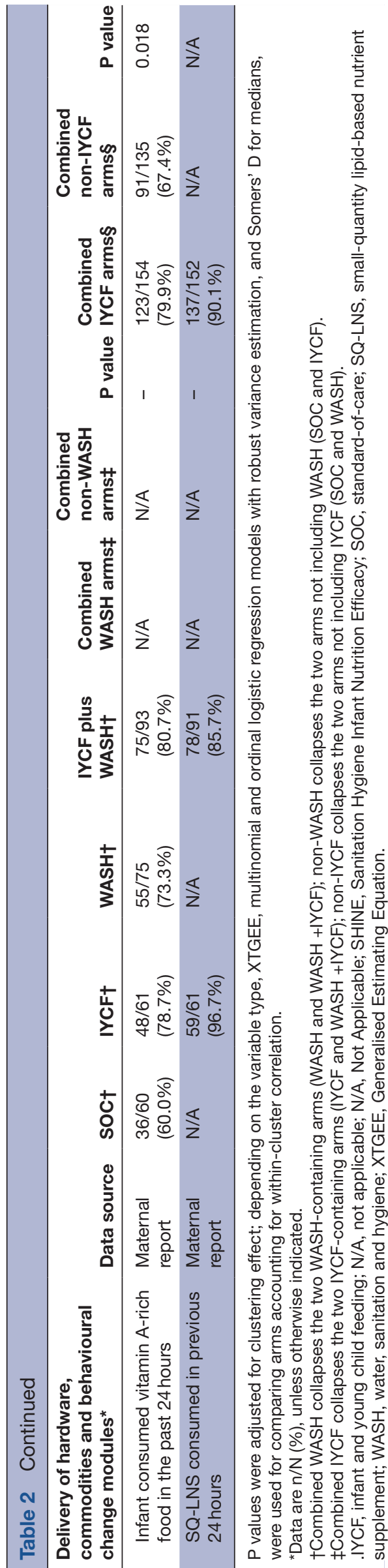

non-WASH arms. There was no evidence of differences between intervention groups in object permanence or in the proportion of children with self-control (table 3). Inferences were similar in adjusted analyses.

\section{Sensitivity and subgroup analyses}

When effects of the interventions were restricted to children confirmed as HEU (ie, removing children who were HIV-positive and HIV-unknown at 18 months of age), overall findings were similar (table 4). There was a significant interaction between child gender and randomised interventions for the total MDAT score. Results stratified by gender showed that among girls, those in the combined IYCF+WASH arm had significantly higher motor, language and social scores than those in the SOC arm. Among boys, those in the combined IYCF+WASH arm had significantly higher language and social scores than those in the SOC arm, but there was no evidence of an intervention effect on motor scores (online supplementary table 2 ).

\section{DISCUSSION}

In this analysis of children born to HIV-positive mothers in rural Zimbabwe, a package combining IYCF and WASH interventions significantly improved motor, language and cognitive development at 2 years of age compared with those receiving enhanced SOC. The same IYCF and WASH interventions when delivered individually (rather than as a combined package) had no impact on ECD at 2 years of age. These findings are contrary to previously reported findings from the SHINE trial among a larger group of 3686 HIV-unexposed children, in whom the IYCF and WASH interventions, delivered either alone or together, had no meaningful impact on ECD. We suggest from these collective findings that HIV exposure in early life is a distinct challenge and that HEU children may be particularly responsive to a package of interventions to improve neurocognitive development.

The SHINE trial was designed to evaluate the effects of IYCF and WASH on linear growth and haemoglobin, which are both associated with child development. In the SHINE trial, among children born to HIV-negative mothers, the IYCF intervention increased LAZ by 0.16 (95\% CI 0.08 to 0.23 ) and haemoglobin by 2.03 (95\% CI 1.28 to 2.79$) \mathrm{g} / \mathrm{L}$ at 18 months of age, while the WASH intervention had no effect on these outcomes. ${ }^{8}$ Among 668 children born to HIV-positive mothers, the effects of the IYCF intervention exceeded those seen in the HIVunexposed group, increasing mean Length for Age Z score (LAZ) by 0.26 (95\% CI 0.09 to 0.43 ) and haemoglobin by $2.9(95 \%$ CI 0.9 to 4.9$) \mathrm{g} / \mathrm{L}$, while the WASH intervention had no effect on these outcomes. ${ }^{9}$ In both analyses, implementing WASH together with IYCF had no additional impact on stunting or anaemia compared with delivering IYCF alone. In the current analysis, HIVexposed children randomised to a package of combined IYCF +WASH interventions had significantly improved 
Table 3 Effect of WASH and IYCF Inventories on early child development at 24 months among HIV-exposed children

\begin{tabular}{|c|c|c|c|c|c|c|c|}
\hline \multirow[b]{2}{*}{$\begin{array}{l}\text { Primary continuous } \\
\text { outcomes }\end{array}$} & \multicolumn{7}{|c|}{ Effects by each randomised arm compared with the SOC ARM } \\
\hline & $\begin{array}{l}\text { Treatment } \\
\text { group }\end{array}$ & $\mathbf{N}$ & Mean (SD) & $\begin{array}{l}\text { Unadjusted difference } \\
(95 \% \mathrm{Cl})\end{array}$ & $P$ value & $\begin{array}{l}\text { Adjusted difference* } \\
(95 \% \mathrm{Cl})\end{array}$ & $\begin{array}{l}P \\
\text { value }\end{array}$ \\
\hline \multirow[t]{4}{*}{ MDAT total score } & SOC & 66 & $90.9(8.2)$ & 0.0 (ref) & & 0.0 (ref) & \\
\hline & IYCF & 66 & $91.7(8.8)$ & $0.81(-1.99$ to 3.61$)$ & 0.572 & $-0.91(-3.40$ to 1.58$)$ & 0.476 \\
\hline & WASH & 83 & $89.6(9.2)$ & $-1.26(-3.80$ to 1.28$)$ & 0.330 & $-1.63(-4.26$ to 0.99$)$ & 0.222 \\
\hline & IYCF+WASH & 103 & $95.3(9.0)$ & 4.57 (1.91 to 7.23$)$ & 0.001 & 3.05 (0.86 to 5.25$)$ & 0.006 \\
\hline \multirow[t]{4}{*}{ MDAT gross motor } & SOC & 66 & $23.1(2.8)$ & 0.0 (ref) & & 0.0 (ref) & \\
\hline & IYCF & 66 & $23.4(2.7)$ & $0.38(-0.50$ to 1.27$)$ & 0.398 & $0.01(-0.88$ to 0.91$)$ & 0.977 \\
\hline & WASH & 83 & $22.7(3.2)$ & $-0.25(-1.00$ to 0.49$)$ & 0.504 & $-0.57(-1.39$ to 0.25$)$ & 0.174 \\
\hline & IYCF+WASH & 103 & $24.3(3.3)$ & 1.50 (0.53 to 2.47$)$ & 0.002 & 0.84 (0.08 to 1.61$)$ & 0.031 \\
\hline \multirow[t]{4}{*}{ MDAT fine motor } & SOC & 66 & $23.0(2.4)$ & 0.0 (ref) & & 0.0 (ref) & \\
\hline & IYCF & 66 & $22.7(3.5)$ & $-0.31(-1.37$ to 0.74$)$ & 0.558 & $-0.50(-1.52$ to 0.51$)$ & 0.329 \\
\hline & WASH & 83 & $22.9(2.6)$ & $-0.10(-0.86$ to 0.66$)$ & 0.804 & $-0.21(-1.11$ to 0.68$)$ & 0.637 \\
\hline & IYCF+WASH & 103 & $23.8(2.6)$ & $0.74(-0.02$ to 1.50$)$ & 0.055 & $0.59(-0.21$ to 1.38$)$ & 0.148 \\
\hline \multirow[t]{4}{*}{ MDAT language } & SOC & 66 & $20.7(3.7)$ & 0.0 (ref) & & 0.0 (ref) & \\
\hline & IYCF & 66 & $20.9(4.2)$ & $0.21(-1.13$ to 1.55$)$ & 0.756 & $-0.65(-1.76$ to 0.46$)$ & 0.250 \\
\hline & WASH & 83 & $20.0(3.9)$ & $-0.73(-1.87$ to 0.41$)$ & 0.209 & $-1.09(-2.24$ to 0.06$)$ & 0.062 \\
\hline & IYCF+WASH & 103 & $22.2(4.1)$ & 1.48 (0.20 to 2.77$)$ & 0.024 & $0.65(-0.33$ to 1.63$)$ & 0.196 \\
\hline \multirow[t]{4}{*}{ MDAT social } & SOC & 66 & $24.1(2.1)$ & 0.0 (ref) & & 0.0 (ref) & \\
\hline & IYCF & 66 & $24.7(2.2)$ & $0.53(-0.00$ to 1.06$)$ & 0.052 & $0.19(-0.37$ to 0.75$)$ & 0.510 \\
\hline & WASH & 83 & $24.0(2.4)$ & $-0.08(-0.70$ to 0.55$)$ & 0.811 & $-0.23(-0.80$ to 0.34$)$ & 0.431 \\
\hline & IYCF+WASH & 103 & $25.0(2.2)$ & 0.99 (0.49 to 1.48$)$ & $<0.001$ & 0.61 (0.13 to 1.09$)$ & 0.013 \\
\hline \multirow[t]{4}{*}{ MacArthur Bates (CDI) } & SOC & 66 & $56.6(18.5)$ & 0.0 (ref) & & 0.0 (ref) & \\
\hline & IYCF & 65 & $57.6(21.3)$ & $1.00(-5.74$ to 7.55$)$ & 0.771 & $-2.47(-8.60$ to 3.67$)$ & 0.431 \\
\hline & WASH & 79 & $58.2(20.1)$ & $1.58(-4.12$ to 7.29$)$ & 0.586 & $-2.27(-8.14$ to 3.60$)$ & 0.448 \\
\hline & IYCF+WASH & 99 & $65.1(17.0)$ & 8.50 (3.66 to 13.33$)$ & 0.001 & 6.01 (1.14 to 10.88$)$ & 0.015 \\
\hline
\end{tabular}

\begin{tabular}{|c|c|c|c|c|c|c|c|c|c|c|}
\hline & \multicolumn{10}{|c|}{ Effects comparing WASH vs non-WASH and IYCF vs non-IYCF } \\
\hline & $\begin{array}{l}\text { Treatment } \\
\text { group }\end{array}$ & $\mathbf{N}$ & Mean (SD) & $\begin{array}{l}\text { Treatment } \\
\text { group }\end{array}$ & $\mathbf{N}$ & Mean (SD) & $\begin{array}{l}\text { Unadjusted } \\
\text { difference }(95 \% \mathrm{Cl})\end{array}$ & $\begin{array}{l}P \\
\text { value }\end{array}$ & $\begin{array}{l}\text { Adjusted } \\
\text { difference }(95 \% \mathrm{Cl})\end{array}$ & $\begin{array}{l}P \\
\text { value }\end{array}$ \\
\hline \multirow{2}{*}{ A not B } & IYCF & 62 & $7.7(1.3)$ & IYCF: yes & 156 & $7.7(1.3)$ & $-0.11(-0.42$ to 0.20$)$ & 0.487 & $0.05(-0.24$ to 0.34$)$ & 0.745 \\
\hline & WASH & 76 & $7.8(1.5)$ & WASH: no & 117 & $7.8(1.3)$ & 0.0 (ref) & & 0.0 (ref) & \\
\hline
\end{tabular}

\begin{tabular}{|c|c|c|c|c|c|c|c|c|c|c|}
\hline $\begin{array}{l}\text { Primary } \\
\text { dichotomous } \\
\text { outcomes }\end{array}$ & $\begin{array}{l}\text { Treatment } \\
\text { group }\end{array}$ & $\mathbf{N}$ & n (\%) & $\begin{array}{l}\text { Treatment } \\
\text { group }\end{array}$ & $\mathbf{N}$ & n (\%) & $\begin{array}{l}\text { Unadjusted } \\
\text { relative risk } \\
(95 \% \mathrm{Cl})\end{array}$ & $\begin{array}{l}P \\
\text { value }\end{array}$ & $\begin{array}{l}\text { Adjusted relative } \\
\text { risk }(95 \% \mathrm{Cl})\end{array}$ & $\begin{array}{l}P \\
\text { value }\end{array}$ \\
\hline \multirow{4}{*}{$\begin{array}{l}\text { Self-control } \\
\text { task (hidden) }\end{array}$} & SOC & 62 & $17(27.4 \%)$ & IYCF: no & 144 & 49 (34.0\%) & 1.00 (ref) & & 1.00 (ref) & \\
\hline & IYCF & 66 & $25(37.9 \%)$ & IYCF: yes & 168 & $58(34.5 \%)$ & $1.00(0.74$ to 1.34$)$ & 0.975 & 1.05 (0.77 to 1.45$)$ & 0.743 \\
\hline & WASH & 82 & $32(39.0 \%)$ & WASH: no & 128 & $42(32.8 \%)$ & 1.00 (ref) & & 1.00 (ref) & \\
\hline & IYCF+WASH & 102 & $33(32.4 \%)$ & WASH: yes & 184 & $65(35.3 \%)$ & 1.08 (0.78 to 1.49$)$ & 0.631 & 0.97 (0.69 to 1.37 ) & 0.878 \\
\hline \multirow{4}{*}{$\begin{array}{l}\text { Self-control } \\
\text { task (unhidden) }\end{array}$} & SOC & 61 & $30(49.2 \%)$ & IYCF: no & 142 & 79 (55.6\%) & 1.00 (ref) & & 1.00 (ref) & \\
\hline & IYCF & 66 & 35 (53.0\%) & IYCF: yes & 166 & $88(53.0 \%)$ & $0.94(0.77$ to 1.41$)$ & 0.522 & 0.92 (0.73 to 1.15$)$ & 0.458 \\
\hline & WASH & 81 & $49(60.5 \%)$ & WASH: no & 127 & $65(51.2 \%)$ & 1.00 (ref) & & 1.00 (ref) & \\
\hline & IYCF+WASH & 100 & $53(53.0 \%)$ & WASH: yes & 181 & $\begin{array}{l}102 \\
(56.4 \%)\end{array}$ & $1.11(0.90$ to 1.36$)$ & 0.350 & 1.09 (0.86 to 1.38$)$ & 0.467 \\
\hline
\end{tabular}

Continued 


\begin{tabular}{|c|c|c|c|c|c|c|c|}
\hline \multirow{2}{*}{$\begin{array}{l}\text { Secondary } \\
\text { dichotomous } \\
\text { language } \\
\text { outcomes }\end{array}$} & \multicolumn{7}{|c|}{ Effects by each randomised arm compared with the SOC ARM } \\
\hline & Treatment group & $\mathbf{N}$ & $\mathbf{N}(\%)$ & $\begin{array}{l}\text { Unadjusted relative risk } \\
(95 \% \mathrm{Cl})\end{array}$ & $\mathbf{P}$ & $\begin{array}{l}\text { Adjusted relative risk } \\
(95 \% \mathrm{Cl})\end{array}$ & $\mathbf{P}$ \\
\hline \multirow[t]{4}{*}{ Uses plurals } & SOC & 66 & $8(12.1 \%)$ & 1.00 (ref) & & 1.00 (ref) & \\
\hline & IYCF & 66 & $17(25.8 \%)$ & 1.97 (0.91 to 4.27$)$ & 0.087 & 1.05 (0.49 to 2.22$)$ & 0.906 \\
\hline & WASH & 83 & $14(16.7 \%)$ & 1.21 (0.51 to 2.88$)$ & 0.667 & 1.15 (0.58 to 2.26$)$ & 0.695 \\
\hline & IYCF+WASH & 103 & $27(26.2 \%)$ & 2.08 (0.98 to 4.41$)$ & 0.055 & 1.57 (0.79 to 3.11$)$ & 0.195 \\
\hline \multirow{4}{*}{$\begin{array}{l}\text { Combines two } \\
\text { words }\end{array}$} & SOC & 66 & $64(97.0 \%)$ & 1.00 (ref) & & 1.00 (ref) & \\
\hline & IYCF & 66 & $63(95.5 \%)$ & 0.99 (0.92 to 1.06$)$ & 0.737 & $0.99(0.92$ to 1.05$)$ & 0.646 \\
\hline & WASH & 83 & $82(98.8 \%)$ & 1.02 (0.97 to 1.07$)$ & 0.407 & 1.01 (0.96 to 1.07$)$ & 0.722 \\
\hline & IYCF+WASH & 103 & 103 (100.0\%) & 1.03 (0.99 to 1.08$)$ & 0.158 & 1.01 (0.97 to 1.06$)$ & 0.566 \\
\hline \multirow[t]{4}{*}{ Uses imperatives } & SOC & 66 & 49 (74.2\%) & 1.00 (ref) & & 1.00 (ref) & \\
\hline & IYCF & 66 & $46(69.7 \%)$ & 0.94 (0.78 to 1.13$)$ & 0.479 & $0.92(0.75$ to 1.11$)$ & 0.380 \\
\hline & WASH & 83 & $57(68.7 \%)$ & 0.91 (0.81 to 1.02$)$ & 0.123 & $0.86(0.71$ to 1.05$)$ & 0.139 \\
\hline & IYCF+WASH & 102 & 77 (75.5\%) & $1.00(0.87$ to 1.15$)$ & 0.973 & $1.01(0.84$ to 1.21$)$ & 0.940 \\
\hline
\end{tabular}

*Scores were adjusted for the following variables: maternal baseline mid-upper arm circumference, education, employment status, CD4 count, cotrimoxazole prophylaxis and antiretroviral treatment during pregnancy, capabilities (perceived physical health and decision-making autonomy), access to improved latrine; infant low birth weight, prematurity, gender and age at assessment; season of recruitment and research nurse who carried out the assessment.

CDI, Communication Development Inventories; IYCF, infant and young child feeding; MDAT, Malawi Developmental Assessment Tool; SOC, standard-of-care; WASH, water, sanitation and hygiene.

motor, social and language development compared with HIV-exposed children receiving SOC interventions; by contrast, those randomised to receive either the IYCF or WASH intervention alone had similar ECD scores to control children. It is difficult to explain why combining IYCF and WASH improved neurodevelopment in HIVexposed children when we found little evidence of benefit from either intervention delivered alone. We did not see this level of synergy between the interventions in HIV-unexposed children, although the study was not powered to distinguish between interactions in these two subgroups. However, among the HIV-exposed children, we found consistent, statistically significant improvements across multiple tests of global child development. These included specific motor, social and language scores, which exhibited substantial magnitudes of effect between IYCF +WASH and SOC of 0.4-0.5 SD. ${ }^{18} 19$ These effect sizes effects are considerable for child development at this age.

We have previously reported that HEU children had evidence of modestly reduced developmental scores compared with HIV-unexposed children in SHINE, ${ }^{20}$ but we suggest from the results of this current study that they may also be more responsive to interventions (online supplementary table 3). The IYCF intervention was designed to improve nutrient intake during a critical period of growth and brain development, while the WASH intervention was designed to reduce exposure to pathogens and to prevent a subclinical inflammatory disorder of the gut termed EED. Perhaps ECD improvements in these vulnerable children are only realised when gut health and nutrient requirements are both addressed simultaneously. A healthier intestinal milieu may facilitate absorption and prevent wastage of nutrients from the IYCF intervention, or modulate the microbiotagut-brain axis to improve neurodevelopment. Further planned laboratory studies of EED biomarkers, pathogen carriage and growth hormone activity will help to address the underlying pathways. We anticipated that the infant feeding intervention alone would lead to improvements in ECD, since IYCF reduced stunting at 18 months of age, but IYCF alone had no evidence of benefit for neurodevelopment. There was no evidence for a synergistic effect of IYCF and WASH on linear growth at 18 months of age, although children randomised to this group did have a larger head circumference (mean Z-score -0.38 , compared with SOC -0.55 , IYCF -0.51 and WASH -0.53 ). It is, therefore, plausible that HIV-exposed children prioritise head growth over linear growth; however, this difference was already apparent from as early as 3 months of age. We are, therefore, uncertain whether our findings reflect a true effect of the combined intervention on ECD, and we also need to consider alternative explanations for these results.

First, it is possible that there was residual confounding in this substudy. Although our findings remained consistent after adjusting for known confounders, there may have been imbalances in unmeasured factors at baseline. This study was nested within a larger randomised controlled trial, where children were identified and offered enrolment during the period of this substudy if they met strict age criteria. There were some differences in rates of enrolment into the ECD study across the treatment arms which may have created bias. There was balance on 
Table 4 Effect of WASH and IYCF inventories on early child development at 24 months among HIV-exposed uninfected children

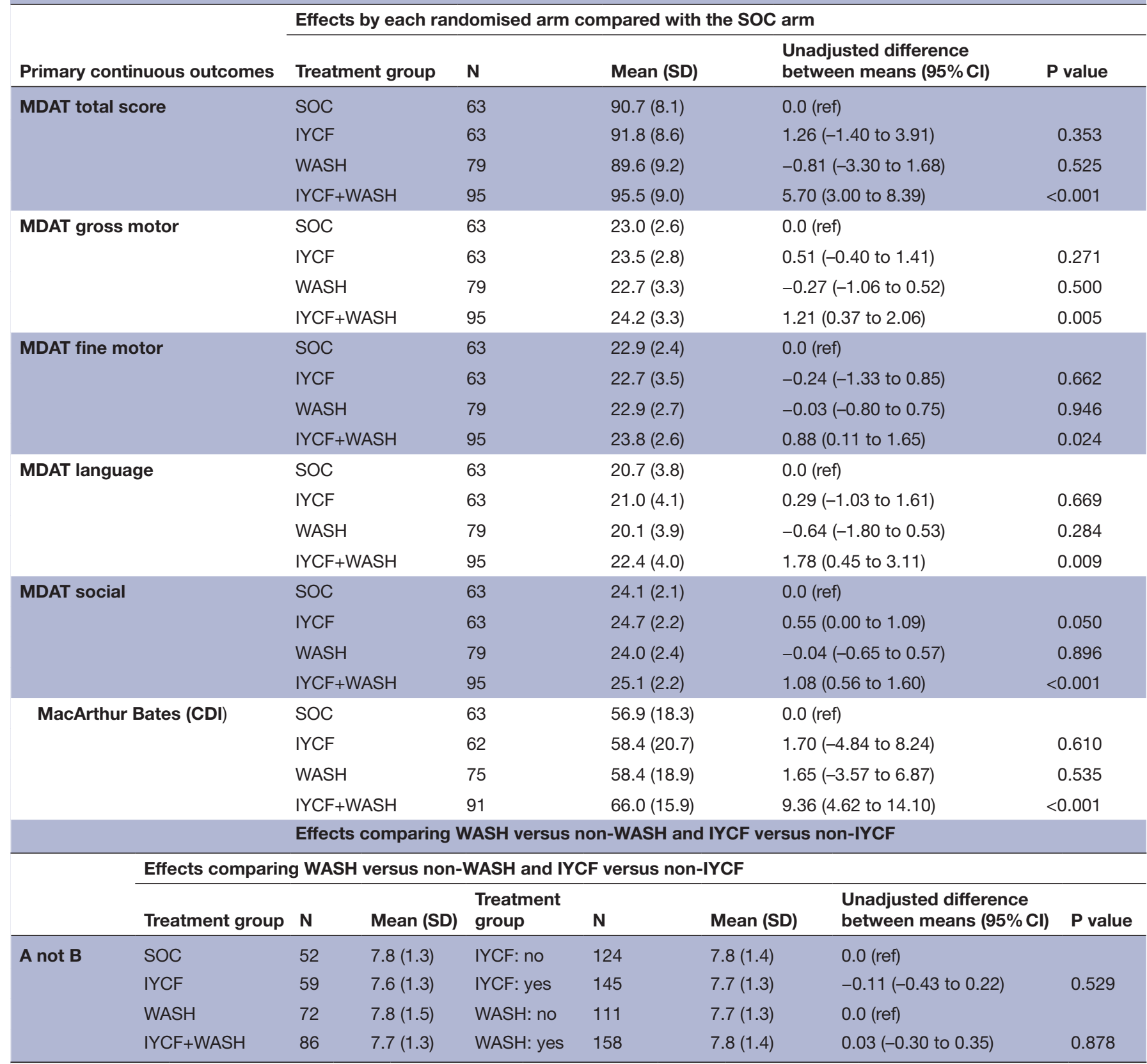

\section{Primary}

dichotomous

outcomes

Treatment

Self-control task

(hidden)

Treatment group

group

N n (\%)

Unadjusted relative risk

$\begin{array}{lllll}\text { IYCF: no } & 137 & 47(34.3 \%) & 1.00 \text { (ref) } & \\ \text { IYCF: yes } & 157 & 53(33.8 \%) & 1.07(0.77 \text { to } 1.49) & 0.698 \\ \text { WASH: no } & 122 & 40(32.8 \%) & 1.00 \text { (ref) } & \\ \text { WASH: yes } & 172 & 60(34.9 \%) & 0.97(0.71 \text { to } 1.32) & 0.839 \\ \text { IYCF: no } & 135 & 74(54.8 \%) & 1.00(\text { ref }) & \\ \text { IYCF: yes } & 155 & 83(53.5 \%) & 0.94(0.77 \text { to } 1.15) & 0.563 \\ \text { WASH: no } & 121 & 61(50.4 \%) & 1.00(\text { ref }) & \\ \text { WASH: yes } & 169 & 96(56.8 \%) & 1.14(0.92 \text { to } 1.41) & 0.219\end{array}$

Continued 
Table 4 Continued

\begin{tabular}{|c|c|c|c|c|}
\hline \multirow[b]{2}{*}{ Secondary dichotomous language outcomes } & \multicolumn{4}{|c|}{ Effects by each randomised arm compared with the SOC ARM } \\
\hline & Treatment group & $\mathbf{N}$ & Unadjusted Relative Risk (95\% Cl) & $P$ value \\
\hline \multirow[t]{4}{*}{ Uses plurals } & SOC & 63 & 1.00 (ref) & \\
\hline & IYCF & 63 & $1.87(0.85$ to 4.12$)$ & 0.118 \\
\hline & WASH & 79 & 1.14 (0.48 to 2.68$)$ & 0.764 \\
\hline & IYCF+WASH & 95 & 2.18 (1.03 to 4.60$)$ & 0.041 \\
\hline \multirow[t]{4}{*}{ Combines two words } & SOC & 63 & 1.00 (ref) & \\
\hline & IYCF & 63 & $1.00(0.94$ to 1.06$)$ & 0.990 \\
\hline & WASH & 79 & $1.02(0.97$ to 1.07$)$ & 0.446 \\
\hline & IYCF+WASH & 95 & * & - \\
\hline \multirow[t]{4}{*}{ Uses imperatives } & $\mathrm{SOC}$ & 63 & 1.00 (ref) & \\
\hline & IYCF & 63 & $0.96(0.80$ to 1.15$)$ & 0.645 \\
\hline & WASH & 79 & 0.93 (0.80 to 1.09$)$ & 0.387 \\
\hline & IYCF+WASH & 95 & 1.01 (0.87 to 1.17$)$ & 0.869 \\
\hline
\end{tabular}

*All the children in the IYCF+WASH arm combined two words.

CDI, Communicative Development Inventories; IYCF, infant and young child feeding; MDAT, Malawi Developmental Assessment Tool;SOC, standardof-care; WASH, water, sanitation and hygiene.

baseline demographics across trial arms for those who were enrolled in the substudy, which increases our confidence in the internal validity of our findings. Overall, there was similarity between those who were enrolled and not enrolled from the main SHINE trial; however, there were some differences that may influence external validity, such as a higher rate of institutional delivery and a shorter walk-time to water in the IYCF+WASHarm among those assessed for ECD compared with those not assessed.

Given our incomplete understanding of the interlinking pathways between HIV exposure and neurodevelopment, it is unlikely that all factors were accounted for in our analyses. For example, it is possible that children in the IYCF-only group had more risk factors (constraints at the maternal, child and household level) for poor ECD which we have not been able to evaluate compared with other groups so that the benefits of the IYCF intervention were only observed in the combined IYCF +WASH group. These risk factors may be related to the caregiver's capacity to provide responsive caregiving, in turn, affecting the child's development. Second, the households in the combined IYCF +WASH group received more trial inputs than the IYCFonly or WASH-only groups. In designing SHINE, we were careful to ensure that all families received the same number of VHW contacts; however, visits in the IYCF +WASHarm were longer and households in the combined IYCF +WASH group received more hardware (latrine and tippy taps) and commodities (chlorine, soap and SQ-LNS) than the IYCF-only or WASH-only groups. Both the IYCF and WASH modules may have increased the interactions between mother and child (eg, washing child's hands and providing responsive feeding) and given the strong evidence linking positive maternal-child interaction and ECD outcomes, it is possible that these combined interventions in some way enabled an increase in interaction time to impact ECD scores. In addition, the positive impact of receiving inputs which included longer visits as well as the material goods (a latrine, tippy tap and nutritional supplements) may have positively impacted maternal mental health and well-being which may have influenced ECD outcomes. ${ }^{21}{ }^{22}$ Quality of caregiving and responsivity plays a critical role within ECD intervention studies and it may be that the additional inputs and VHW time that were provided in the combined group with both curricula improved maternal well-being and enabled increased responsivity more in the vulnerable HIV-positive women than in HIV-negative women, and this, in turn, improved ECD in their children. In other words, the 'double' training pack received from VHWs along with the additional inputs may have enabled mothers to be more responsive to the health and developmental needs of their HEU children. This may also reflect the fact that we saw a specific neurodevelopmental profile change in the areas of language and fine motor development (both closely linked to responsive caregiving) than in the gross motor and social components of development. With this in mind, a package of interventions which enhances quality caregiving and responsivity as much as possible may be what is needed to meaningfully impact ECD.

We found a significant interaction between child gender and trial intervention. Among girls, compared with the SOC arm, those in the combined IYCF+WASH arm had significantly higher motor, language and social scores. Among boys, compared with the SOC arm, those in the combined IYCF+WASHarm had significantly higher language and social scores, but there was no evidence of an effect on motor scores. Among children in the SOC arm, boys generally had poorer language and social scores than girls, whereas motor scores were similar; it is possible that whereas girls generally responded to IYCF+WASH interventions in all domains, boys only responded when developmental delays were more pronounced. 
This analysis has several strengths. To our knowledge, this is the first intervention trial evaluating ECD outcomes in HIV-exposed children, who are an expanding population in regions with high ongoing antenatal HIV prevalence. By using several different developmental assessment tools, we were able to thoroughly assess ECD across a broad range of domains. We adapted our assessment tools for use in rural Zimbabwe, and undertook extensive piloting, quality control and standardisation. We were able to report the findings specifically for HEU children, who now comprise the vast majority of children born to HIV-infected mothers. However, an important limitation of this study is that SHINE was originally designed to assess the effects of IYCF and WASH interventions on stunting and anaemia, and was powered to evaluate these outcomes in HIV-unexposed children; the ECD component was a substudy of the trial, and the current findings focus only on HIV-exposed children. Further studies are needed to confirm our findings in other populations.

In summary, HIV-exposed children randomised to a combined intervention of improved ICYF and improved WASH had significant improvements in ECD at 2 years of age, while those receiving either the IYCF or WASH intervention alone had no evidence of ECD benefit. Importantly, combining the IYCF and WASH interventions closed the developmental gap between HEU and HIV-unexposed children. Although the mechanisms that underlie the synergistic effects of IYCF and WASH on ECD in HIV-exposed children remain unclear, our study implicates nutrition and WASH as contributing factors in the neurocognitive development of children exposed to HIV in early life that warrant further study. Thus, despite having poorer health outcomes than HIV-unexposed children in the absence of any interventions, we suggest from the results of this study, that HEU children may be more responsive to public health interventions. The interventions we provided combined WASH improvements with nutritional support, which goes beyond what current PMTCT programmes provide. Combining these approaches with specific nurturing care and early education interventions, in line with the Nurturing Care Framework strategy, may bring additional benefits to improve human capital in this expanding global population.

\section{Author affiliations \\ ${ }^{1}$ Department of Women and Child Health, University of Liverpool, Liverpool, UK ${ }^{2}$ Zvitambo Institute for Maternal and Child Health research, Harare, Zimbabwe ${ }^{3}$ Centre for Genomics and Child Health, Blizard Institute, Queen Mary University of London, London, UK \\ ${ }^{4}$ University of Zimbabwe College of Health Sciences, Harare, Zimbabwe \\ ${ }^{5}$ Global Alliance for Improved Nutrition, Washington, DC, USA \\ ${ }^{6}$ Department of International Health, Johns Hopkins Bloomberg School of Public Health, Baltimore, Maryland, USA}

Twitter Jaya Chandna @jayachandna, Robert Ntozini @NtoziniRobert and Melissa Gladstone @mjgladstone

Acknowledgements The SHINE trial was funded by the Bill \& Melinda Gates Foundation (OPP1021542 to Johns Hopkins Bloomberg School of Public Health and OPP1143707 to Zvitambo Institute for Maternal and Child Health Research); the United Kingdom Department for International Development (DFID/UKAID); Wellcome Trust (093768/Z/10/Z, 108065/Z/15/Z and 203905/Z/16/Z); Swiss Agency for Development and Cooperation (8106727); UNICEF (PCA-2017-0002); National Institutes of Health (R01 HD060338/HD/NICHD). We thank all the mothers, babies and their families who participated in SHINE. We gratefully acknowledge the leadership and staff of the Ministry of Health and Child Care in Chirumanzu and Shurugwi districts and Midlands Province (especially environmental health, nursing and nutrition) for their roles in operationalisation of the study procedures. We acknowledge the Ministry of Local Government officials in each district who supported and facilitated field operations. We are particularly indebted to Phillipa Rambanepasi and her team for proficiently managing all the finances and Virginia Sauramba for managing compliance issues. Finally, we are very thankful for our programme officers at the Gates Foundation and DFID who enthusiastically worked with us over a long period of time to make SHINE happen.

Contributors JC was involved with data curation, formal analysis, methodology, project administration, validation, writing —original draft, writing — review and editing. RN was involved with data curation, formal analysis, methodology, validation, writing - review and editing. CE was involved with formal analysis, methodology, writing — original draft, and writing — review and editing. GK was involved with conceptualisation, methodology, supervision, validation, writing — review and editing. BC was involved with data curation, formal analysis, methodology and reviewing and editing. FM was involved with data curation, methodology, project administration, validation, writing — review and editing. KM was involved with data curation, methodology and review and editing. NT was involved in data curation, methodology, project administration, writing —review and editing. BM was involved in data curation, analysis and review and editing. MM was involved in conceptualisation, data curation, funding acquisition, investigation, methodology, project administration, resources, supervision, writingreview and editing. LHM was involved in conceptualisation, formal analysis, investigation, methodology, writing — review and editing. JHH was involved with conceptualisation, data curation, funding acquisition, investigation, methodology, project administration, resources, supervision, writing - review \& editing. AP was involved with conceptualisation, data curation, funding acquisition, investigation, methodology, project administration, resources, supervision, writing — review and editing. MG was involved with conceptualisation, data curation, methodology, supervision, validation, writing—original draft, writing—review and editing.

Funding Funded by the Bill \& Melinda Gates Foundation (OPP1021542 and OPP1143707); the United Kingdom Department for International Development (DFID/UKAID); Wellcome Trust (093768/Z/10/Z, 108065/Z/15/Z and 203905/Z/16/Z); Swiss Agency for Development and Cooperation; US National Institutes of Health (2R01HD060338-06); and UNICEF (PCA-2017-0002).

\section{Competing interests None declared.}

Patient consent for publication Not required.

Ethics approval The Medical Research Council of Zimbabwe and the Institutional Review Board of the Johns Hopkins Bloomberg School of Public Health approved the study protocol.

Provenance and peer review Not commissioned; externally peer reviewed.

Data availability statement Data are available on request. Data will be freely available as individual participant data with an accompanying data dictionary at $\mathrm{http} / / /$ ClinEpiDB.org from late 2019. This platform is charged with ensuring that epidemiological studies are fully anonymised by removing all personal identifiers and obfuscating all dates per participant through application of a random number algorithm to comply with the ethical conduct of human subjects research.

Researchers must agree to the policies and comply with the mechanism of ClinEpiDB to access data housed on this platform. Prior to that time, the data are housed on the ClinEpiDB platform at the Zvitambo Institute for Maternal and Child Health Research and available on request from Virginia Sauramba (vsauramba@ zvitambo.co.zW).

Open access This is an open access article distributed in accordance with the Creative Commons Attribution 4.0 Unported (CC BY 4.0) license, which permits others to copy, redistribute, remix, transform and build upon this work for any purpose, provided the original work is properly cited, a link to the licence is given, and indication of whether changes were made. See: https://creativecommons.org/ licenses/by/4.0/.

\section{ORCID iDs}

Jaya Chandna http://orcid.org/0000-0001-9836-0554

Robert Ntozini http://orcid.org/0000-0002-8543-2835

Mduduzi NN Mbuya http://orcid.org/0000-0003-1230-2367 
Melissa Gladstone http://orcid.org/0000-0002-2579-9301

\section{REFERENCES}

1 UNAIDS. Available: http://aidsinfo.unaids.org

2 Evans C, Jones CE, Prendergast AJ. Hiv-Exposed, uninfected infants: new global challenges in the era of paediatric HIV elimination. Lancet Infect Dis 2016;16:e92-107.

3 Prendergast AJ, Humphrey JH. The stunting syndrome in developing countries. Paediatr Int Child Health 2014;34:250-65.

4 Walker SP, Wachs TD, Grantham-McGregor S, et al. Inequality in early childhood: risk and protective factors for early child development. The Lancet 2011;378:1325-38.

5 John CC, Black MM, Nelson CA. Neurodevelopment: the impact of nutrition and inflammation during early to middle childhood in lowresource settings. Pediatrics 2017;139:S59-71.

6 McHenry MS, McAteer Cl, Oyungu E, et al. Neurodevelopment in young children born to HIV-infected mothers: a meta-analysis. Pediatrics 2018;141:e20172888.

7 Humphrey $\mathrm{JH}$, Jones AD, Manges $\mathrm{A}$, et al. The sanitation hygiene infant nutrition efficacy (shine) trial: rationale, design, and methods. Clin Infect Dis 2015;61:S685-702.

8 Humphrey JH, Mbuya MNN, Ntozini R, et al. Independent and combined effects of improved water, sanitation, and hygiene, and improved complementary feeding, on child stunting and anaemia in rural Zimbabwe: a cluster-randomised trial. The Lancet Global Health 2019;7:e132-47.

9 Prendergast AJ, Chasekwa B, Evans C, et al. Independent and combined effects of improved water, sanitation, and hygiene, and improved complementary feeding, on stunting and anaemia among HIV-exposed children in rural Zimbabwe: a cluster-randomised controlled trial. The Lancet Child \& Adolescent Health 2019;3:77-90.

10 Gladstone MJ, Chandna J, Kandawasvika G, et al. Independent and combined effects of improved water, sanitation, and hygiene (wash) and improved complementary feeding on early neurodevelopment among children born to HIV-negative mothers in rural Zimbabwe: substudy of a cluster-randomized trial. PLoS Med 2019;16:e1002766.

11 Gladstone M, Lancaster GA, Umar E, et al. The Malawi developmental assessment tool (MDAT): the creation, validation, and reliability of a tool to assess child development in rural African settings. PLoS Med 2010;7:e1000273.

12 Fenson L, Marchman VA, Thal DJ PSD, et al. Communicative development inventory) words and sentences. Baltimore, Maryland: Brookes Publishing, 2007.

12 Macarthur Bates CDI Adaptations. Available: https://mb-cdi. stanford.edu/adaptations.html [Accessed October 11, 2018].

14 Prado EL, Phuka J, Ocansey E, et al. A method to develop vocabulary checklists in new languages and their validity to assess early language development. J Health Popul Nutr 2018;37:13.

15 Espy KA, Kaufmann PM, McDiarmid MD, et al. Executive functioning in preschool children: performance on A-not-B and other delayed response format tasks. Brain Cogn 1999;41:178-99.

16 Nampijja M, Apule B, Lule S, et al. Effects of maternal worm infections and anthelminthic treatment during pregnancy on infant motor and neurocognitive functioning. J Int Neuropsychol Soc 2012;18:1019-30.

17 Workgroup WCD. Module on child functioning and disability. Washington Centre for Disease Control, 2014.

18 Sim F, Thompson L, Marryat L, et al. Predictive validity of preschool screening tools for language and behavioural difficulties: a PRISMA systematic review. PLoS One 2019;14:e0211409.

19 Gandhi M, Teivaanmaki T, Maleta K, et al. Child development at 5 years of age predicted mathematics ability and schooling outcomes in Malawian adolescents. Acta Paediatr 2013;102:58-65.

19 Chandna J, Evans C, Chasekwa B, et al. Early child development of HIV-exposed uninfected children in rural Zimbabwe. In: Conference on retroviruses and opportunistic infections (CROI. Seattle: (WA), 2019.

21 Cummings EM, Davies PT. Maternal depression and child development. J Child Psychol \& Psychiat 1994;35:73-122.

22 Petterson SM, Albers AB. Effects of poverty and maternal depression on early child development. Child Dev 2001;72:1794-813

23 Chasekwa B, Maluccio JA, Ntozini R, et al. Measuring wealth in rural communities: lessons from the Sanitation, Hygiene, Infant Nutrition Efficacy (SHINE) trial. PLoS One 2018;13:e0199393.

24 Maxwell D, Watkins B, Wheeler R, et al. The coping strategy index: a tool for rapid measurement of household food security and the impact of food aid programsprogramme in humanitarian emergencies. Nairobi: CARE and WFP, 2003. 